\title{
Reformation of "three in one" Entrepreneurship Education Model
}

\section{WU}

School of Mechanical Engineering, Hangzhou Dianzi University, Hangzhou, China;

\section{Y. CHEN}

The College of Business Administration, Zhejiang University of Finance \& Economics, Hangzhou, China

\begin{abstract}
Entrepreneurship education is gradually becoming an important part of the global development strategy of colleges and universities. Zhejiang provincial undergraduate colleges implement "Zhejiang mode" of entrepreneurship education relying on the developed private economy and the innovative cultivation practice. This article selects Ningbo University, Zhejiang Normal University, Zhejiang University of Technology, Hangzhou Dianzi University, in order to analyze the models of entrepreneurship education, experiences, and their respective characteristics. They are both comprehensive and professional, both in science and engineering, economics and management, and education areas. Finally, the paper reforms the three-in-one entrepreneurship education model from basic level, operation level, system level of Hangzhou Dianzi University.
\end{abstract}

KEYWORD: Entrepreneurship Education; Three-in-one; Zhejiang Experiences; Model Reformation

\section{GLOBAL DEVELOPMENT TREND AND CHINESE TYPE OF ENTREPRENEURSHIP EDUCATION}

The first World Conference on Higher Education was held by UNESCO in 1998 in Paris, France. The meeting adopted two important reports as " World Declaration on Higher Education for the Twenty-first Century: Vision and Action" and "Framework for Priority Action for Change and Development in Higher Education ", which stressed that "Entrepreneurial skills and entrepreneurship of the students should be trained as the basic goal of higher education."[1] Entrepreneurship education is becoming an important part of the global development strategy of universities, The United States has more than 1100 colleges and universities offer courses in the field of entrepreneurship.

Chinese Ministry of Education organized experts to investigate students and university staff in Beijing, Shanghai, Guangdong, Zhejiang, Liaoning and Anhui provinces in 2008. Entrepreneurship education in Chinese universities is collated into six basic types as follows [2]: (1) Taking Entrepreneurship education into the school-wide curriculum system (mainly in vocational schools); (2) Constructing the students entrepreneurial base as a platform. (3) Government promotion (building entrepreneurship education demonstration school); (4) Centering around the "Challenge Cup" and "business plan" contest; (5) Taking entrepreneurship education into careers teaching; (6) Leading other international and social entrepreneurship education into universities, including mainly the "college students KAB entrepreneurship foundation course" initiated by the National Youth Federation and the ILO and "Start Your Business" program (SYB) introduced by the Ministry of Labor and Social Security in cooperation with the ILO.

\section{ZHEJIANG COLLEGE EXPERIENCE}

Zhejiang is the vanguard of high-speed private economic development. Zhejiang created $7.5 \%$ of China's GDP with nearly $1 \%$ of the land and $4 \%$ of the population. Among them, private economy in Zhejiang has contributed more than $60 \%$ of the revenue, more than 70 percent of GDP, more than $80 \%$ of exports and more than $90 \%$ of new jobs. Zhejiang private enterprises are accounted for 203 seats among 500 National Private Economy [3]. Colleges in Zhejiang firmly establish the concept of local services and always focus on economic and social development needs. They linked closely personnel training, scientific research and social service by scientific research, technological innovation, regions service. And they forged ahead along a road, which means that Expanding business practices channels rely on regional economy, excavating cultural heritage and inheriting four thousand spirits of Zhejiang businessmen. Furthermore, they reclaimed solid theoretical and practical fertile riverbed for entrepreneurship education. 


\subsection{Ningbo University "platform \& Module \& Window" Entrepreneurship education mode}

Ningbo University is an emerging local comprehensive university which grows up during Reform and Opening. It is built by Zhejiang Province, Ningbo City, and the Ministry of Education. Currently the school has developed into a comprehensive teaching and research university, and its' comprehensive strength has entered into the top 100 colleges in China. Many people called "Ningbo Bang" and "Bang Ningbo" from home and abroad give a lot of help and wide support in the process of creation and development of school.

Ningbo University has built a "penetration curriculum, training guides, management first" and "Three in one" entrepreneurship education mode, mainly relied on "platform \& Module \& Window" training mode insisted by school [4]. With the college students' innovative entrepreneurial training program platform, student ware educated to innovate, develop in an appropriate way to pursue opportunities, create social value and seeking career growth. It is the foundation of the innovation service. The platform is integrated by the second classroom activities such as the student extracurricular activities of science and technology, science and technology competition, cultural accomplishment and ideological quality education, lectures, club activities, brand theory and humanistic class competitions, the sports activities and social practice, vocational skills training, etc.

"Module" education included technology development, the transformation, marketing, business management, economic regulation, and other basic business knowledge, which is the embodiment of the specialization of college students' entrepreneurial quality. School equips with laboratory research and development, business incubation base modules carries out shunt education scientifically and breaks the "general education" mode according to each class's characteristics of the technological class, the service class, and complex entrepreneurial projects.

"Window" education designed science and technology competition window, investment financing window, corporate collaboration window, patent application window and commercial window to set up a bridge of social practice for students' entrepreneurial projects.

\subsection{College of Zhejiang Normal University entrepreneurship education mode}

Zhejiang Normal University is a multidisciplinary provincial key university focusing mainly on teacher education. Collage adheres to the employment concept that everything is for the graduates, for all graduates, attaches great importance to the cultivation of entrepreneurship and innovation and entrepreneurship ability training and sets up a special institute for innovation and entrepreneurship which aims to "create innovative Normal, foster entrepreneurial elite".

Institute for Innovation and Entrepreneurship school opens to sophomore junior recruit students, and has one semester year. After graduating, students will be awarded with a certificate of completion, as well as two credits of innovation and entrepreneurship education by Zhejiang Normal University Innovation and Entrepreneurship Institute. Innovation and entrepreneurship institute regards entrepreneurship, business knowledge and entrepreneurial training as teaching's focus, and Lize business base, school flea market and entrepreneurial community development as the main teaching carrier, introduces brainstorming, role-playing and other interactive teaching methods, carry out a full program to track, three-dimensional coverage, systematic operation and personalized guidance entrepreneurship education model. Based on the effective implementation of the mode, Zhejiang Normal University College of entrepreneurship education Gradually builds up "to enhance business awareness, cultivate entrepreneurship and building entrepreneurial base, innovation and entrepreneurship mechanism" four in one working system [5], including inspiring college students pioneering consciousness by cultivating the innovative spirit; strengthening college students' entrepreneurial skills by cultivating comprehensive ability; increasing business achievements through entrepreneurship practice base and improving the success rate of entrepreneurship through innovative business mechanism.

\subsection{Entrepreneurship Awareness excitation mode of Zhejiang University of Technology}

Zhejiang Sci-Tech University is mainly for Science and Technology. Textiles and clothing are the featured disciplines in the university. Independent brand created by the school graduates account for the half in "Hang Brand Dress".

In innovation and entrepreneurship's education, the school puts forward that promoting entrepreneurship education is the most important part to stimulate entrepreneurial consciousness. Thus, concentrating on entrepreneurship education and patriotic education, case education, career planning education and career development guidance "three combinations" to educate students to take the initiative to put their entrepreneurial themselves combined with the revitalization of the nation's development, consciously forge creative personality and establish entrepreneurial vision; alumni report, entrepreneurs forum and other forms of success after entrepreneurship can make the students realize the importance of the value of their own to realize that the risk of the entrepreneurial process and have the ability and quality requirements to establish a sense of frustration in the future to go smoothly their own 
entrepreneurial path, and clear direction to strive; through employment and entrepreneurship associations, future Entrepreneurs Association, KAB clubs and other community organizations three college students venture activities, the school has developed a shape of "alumni talent model room", a strong cultural atmosphere to stimulate student awareness of entrepreneurship [6].

\section{HDU'S "THREE IN ONE" \\ ENTREPRENEURSHIP EDUCATION REFORMATION IDEAS}

\subsection{Problems of entrepreneurship education in $H D U$}

Hangzhou Dianzi University (HDU) is an institution of higher learning that offers multiple disciplines, including engineering, science, economics, management, literature, law and education. While highlighting electronics and information science, the university is also fairly strong in the disciplines of business management.
However, its entrepreneurship education is mainly in the infancy period. On the one hand, the government-led entrepreneurship education can't keep touch with the market, resulting in students performing blindly out of the reality, entrepreneurial vision is difficult to enter the actual operation phase; on the other hand, the core elements of entrepreneurship education (including teachers, curriculum, capitals, internal and external alliances) lack of systematic, professionalism, diversity, which can easily lead to the stagnated development.

\subsection{HDU's reconstruction "three in one" of entrepreneurship education model}

HDU need to put the emphasis on entrepreneurship education, by setting up a leading group, entrepreneurship education centers, expert group, advisory committee and other students organizations. The reconstruction is composed from basic level, operational level and the institutional level [7].

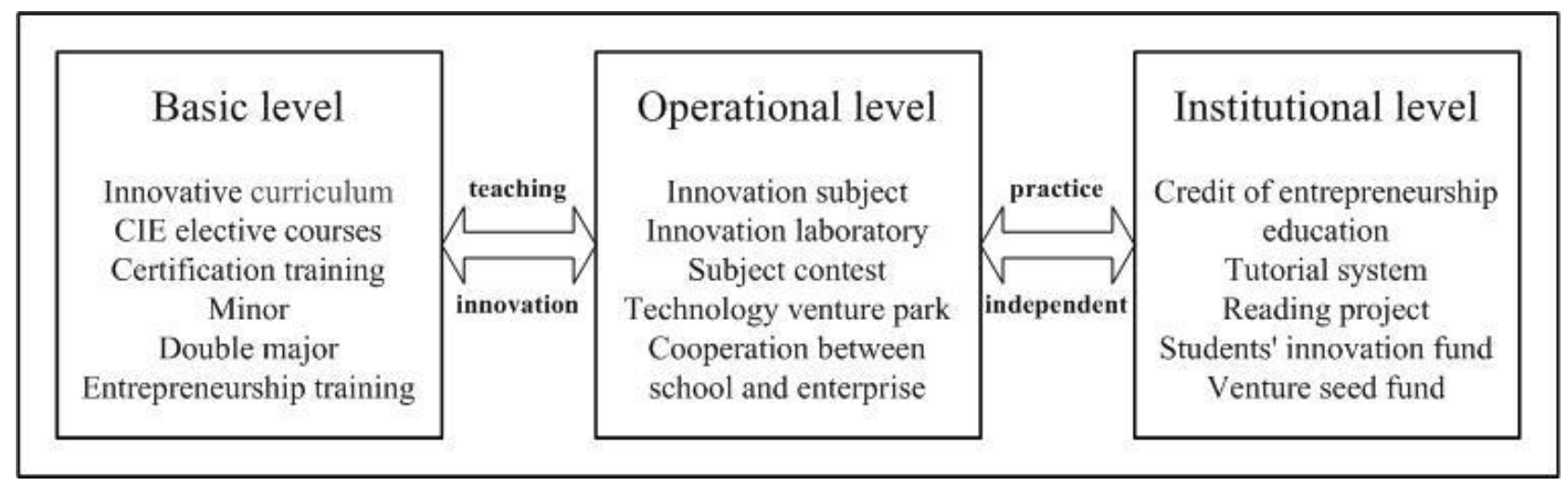

Figure 1. "Three in one" Entrepreneurship education system schematic diagram

\subsubsection{Basic Level}

HDU sets the credit as a platform to strengthen the curriculum module construction, leading the students to enhance the sense of innovation, the formation of entrepreneurial thinking.

(1) Design innovative teaching programs to foster students' exposure to the frontiers of knowledge. Each teaching unit set up a number of frontier crossing theoretical courses to explore new innovative teaching modes. HDU should advocate teachers to combine with disciplines, hot issues and crossdisciplinary research in lectures, and bring students to play the role of overall optimization professional training programs.

(2) Design special elective courses to promote interactive teaching and learning. Apart from the innovative curriculum, HDU should set up elective courses of "creativity, innovation, entrepreneurship" by formal theoretical lectures, practical lessons and occupations role play. The examination and evaluation approaches need to be innovative as well, which require teachers to constantly update the teaching content and well-designed lesson plans, focusing on innovative curriculum, interactive and integrated with the practice.

(3) Design certification training courses to promote students competitiveness in the job market. HDU should open certification training courses to enable students qualified for professional business market by achieving professional knowledge and skills for college graduates.

(4) Design double major programs to promote interdisciplinary knowledge. HDU should design double major programs to encourage students to study in the interdisciplinary professional, obtaining other discipline way of thinking, improving the ability of autonomous learning.

(5) Design entrepreneurial training programs to promote students to master entrepreneurship skills. The projects like SIYB (Start and Improve Your Business), KAB (Know about Business) are all excellent entrepreneurial training programs to be imported by HDU to improve students' awareness of entrepreneurship and entrepreneurial capabilities. In 
teaching practice, it gradually forms a complete teaching system of "Training Needs Analysis Teaching program design - Courses Available Participant Selection - Implementation Training ongoing support - performance tracking".

\subsubsection{Operational level}

HDU should strengthen the practice platform to explore students' autonomy and diversity practical abilities.

(1)To carry out innovative project establishment and achievement assessment to promote student innovative research practice. HDU should set fund on student research projects to encourage students actively participate in research and innovation. Then the school's positive atmosphere for scientific research is set to improve students' ability to play an important role in practice.

(2) To carry out Innovation Lab project management to promote student participation in research earlier. Innovation Lab project management provides students with independent topics, independent design and independent practice space. It trains students the basics of the experiment, methods and skills.

(3) To carry out academic competitions to promote students to show their talent. Practice shows that the academic competitions not only stimulate student interest in scientific research, expand the students' thinking imagination and rich the practical experience, but also enable students to show their talent, exercise capacity and improve the quality.

(4) To set out Technology Park to incubate Student entrepreneurial practice. The Technology Park will become an important practice platform in bringing up the students' ability of innovation and entrepreneurship.

(5) To strengthen school-enterprise cooperation to promote effective communication. HDU should create channels for businesses communicate through practice bases, training centers, business mentor, etc., with keynote presentations, case studies and other means to maintain regular communication with students.

\subsubsection{Institutional level}

University focused on deepening the quality of education and improving teaching quality. On the basis of the existing quality education system construction, it strengthened the construction of rule module, guaranteed the deepening and improvement of quality education which point to entrepreneurship education.

(1) To set entrepreneurship education credits to optimize student credit structure

The entrepreneurship education credits are constituted of reading credits and innovation credits to expand students knowledge and improve exercise capacity.
(2) To establish academic mentor to achieve customized guide for students

Tutors charisma, academic and life experiences can exert a subtle influence on the growth and success of students. HDU implements a comprehensive mentoring within the school to guide the students.

(3) To implement reading project to enhance students' cultural literacy

Reading project has played an important role in broaden student their horizons and improve the overall quality of students in the humanities.

(4) To establish Student Innovation Fund and Seed fund to support students practice

In order to achieve the standard management, HDU organize expert review and give the amount to students in different levels. In addition, it strengthens the use of the process and evaluation of practice results.

\section{ACKNOWLEDGMENTS}

The research work described in this paper was supported by Hangzhou Dianzi University Reform and Innovation on Class Teaching Project under Grant No. KT1402, Scientific Research Fund of Zhejiang Provincial Education Department under Grant No. Y201120741 and Scientific Research Fund of Zhejiang Provincial Culture Department under Grant No. ZW2014072.

\section{REFERENCES}

[1] Cao S. Entrepreneurship education led to the cultivation of innovative talents. China Education Daily, 7th edition March 26, 2008.

[2] Duan L. Strengthening entrepreneurship education. Guangming Daily, August 11, 2007.

[3] Entrepreneurial and innovation make Zhejiang flourishing. People's Daily, October 25, 2011.

[4] Zhou Q, Zhao fa. "Three in one": Entrepreneurship Education Model Construction and Operation Experiences from Ningbo University. China Higher Education Research, 2009, 4: 84-85.

[5] Zhou B. One of the four practice and innovation cycle model of pioneering education - Zhejiang Normal University. Chinese graduate employment, 2008, 22: 6364.

[6] Carry forward the fine traditions of the school and foster innovation and entrepreneurship - entrepreneurship education experience, Zhejiang University of Technology introduced [EB / OL]. Baidu library, http://wenku.baidu.com/view/58c39cc189eb1 72ded63b7f5.html.

[7] Zhang Z. Experimental area of professional education based on entrepreneurship training model innovation and reform. The Ministry of Education personnel training model innovation experimental area declarations, 2008. 